\title{
COLECISTITE AGUDA DE CORRENTE DE HEMORRAGIA INTRALUMINAR DA VESÍCULA BILIAR APÓS TRAUMA ABDOMINAL FECHADO
}

\author{
POSTTRAUMATIC ACUTE CHOLECYSTITIS CAUSED BY INTRA-GALLBLADDER \\ HEMORRHAGE
}

\section{Renato Manganelli Salomão, TCBC-RJ' ; Nycole Carvalho Magalhães, AsCBC.²; Flávio Volpato da Silva, AsCBC ${ }^{3}$; Antonio Carlos Iglesias, TCBC-RJ}

\section{INTRODUÇÃO}

A lesão traumática da vesícula biliar (VB) é pouco freqüente, sua incidência global varia de 0,8 a 2,1\% em pacientes que apresentam algum tipo de traumatismo abdominal ${ }^{1-}$ ${ }^{4}$. Dentre as suas diferentes formas, a colecistite traumática após hemorragia intraluminal, oriunda da própria VB é a mais $\operatorname{rara}^{2,3,5}$.

Neste estudo relataremos o caso de paciente vítima de trauma fechado da região tóraco-abdominal direita (RTAD) que evoluiu com dor no quadrante superior correspondente e melena, seguido de colecistite aguda.

\section{RELATO DO CASO}

Paciente masculino, 29 anos de idade, vítima de agressão física há 15 dias, foi internado referindo dor de forte intensidade na RTAD. Diagnosticou-se fratura da $10^{\mathrm{a}}$ costela direita. Recebeu alta, porém com a piora da dor procurou outro hospital, onde realizou ultra-sonografia abdominal (USA) que mostrou fígado de aspecto habitual, VB de paredes espessadas e conteúdo heterogêneo - anecóico com elementos sólidos e presença de líquido livre em pequena quantidade nos espaços hepato-renal e perivesicular (Figura 1A). O hematócrito era de $31 \%$ e a hemoglobina de $11 \mathrm{~g} / \mathrm{dL}$. Após 24 horas recebeu alta.

Ao internar-se no Hospital Universitário GaffréGuinle, o paciente queixava-se de dor contínua de forte intensidade em quadrante superior direito do abdome. Referia febre, dois episódios de melena e vômitos alimentares e biliosos. Estava hemodinamicamente estável, hipocorado e a temperatura axilar era de $37,2 \mathrm{C}^{\circ}$. Apresentava equimoses na parede ântero-lateral direita do tórax e do abdome. À palpação do gradil costal direito referia dor na projeção da $10^{\mathrm{a}}$ costela.
Havia discreto abaulamento no hipocôndrio direito e dor à palpação superficial e profunda nesta região com Sinal de Murphy presente; hematócrito de 28,4\%, hemoglobina de 8,6 $\mathrm{g} / \mathrm{dL}$, leucócitos de $5300 / \mathrm{mm}^{3}$; bilirrubina total de $1,4 \mathrm{mg} \%$ com $0,9 \mathrm{mg} \%$ de bilirrubina direta. A endoscopia digestiva alta não evidenciou qualquer alteração que justificasse os episódios de melena. A USA mostrou fígado de aspecto habitual, VB aumentada de volume, com paredes espessadas, com material ecóico em seu interior sugestivo de coágulo; e pequena quantidade de líquido perivesicular (Figura 1B). Feita a hipótese diagnóstica de colecistite traumática, a colecistectomia teve início por abordagem videolaparoscópica, convertida para

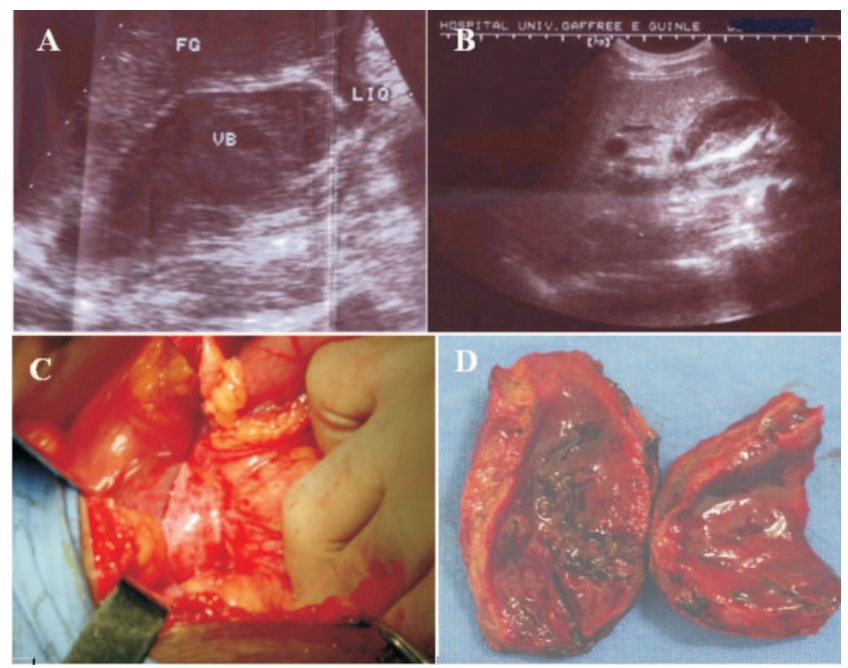

Figura 1 - Em A USA mostra líquido pericolecístico e VB com conteúdo anecóico e elementos sólidos; em $B$ a segunda USA revela $V B$ de paredes espessadas, com conteúdo ecóico sugestivo de hematoma. $C$ - aspecto do campo operatório onde se observa a aderência entre a $V B$ e as estruturas adjacentes; em D peça cirúrgica onde se destaca $o$ espessamento parietal e a laceração parcial da parede da VB.

1. Professor Associado da Disciplina de Clínica Cirúrgica "A" da Escola de Medicina e Cirurgia; Cirurgião do Serviço de Cirurgia Geral e Aparelho Digestivo - $6^{\text {a }}$ Enfermaria do Hospital Universitário Gaffrée-Guinle. Universidade Federal do Estado do Rio de Janeiro - UNIRIO.

2. Residente do Serviço de Cirurgia Geral e Aparelho Digestivo - $6^{a}$ Enfermaria - do Hospital Universitário Gaffrée-Guinle da Universidade Federal do Estado do Rio de Janeiro - UNIRIO.

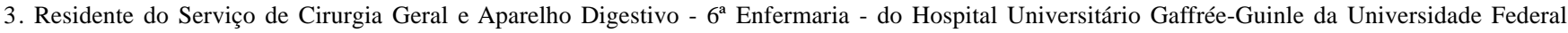
do Estado do Rio de Janeiro - UNIRIO.

4. Professor Titular da Disciplina de Clínica Cirúrgica "A" da Escola de Medicina e Cirurgia; Chefe do Serviço de Cirurgia Geral e Aparelho Digestivo

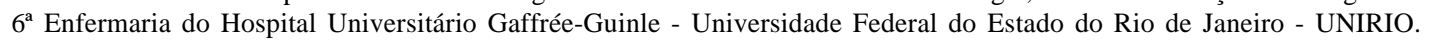

Recebido em 10/02/2006

Aceito para publicação em 20/03/2006

Trabalho realizado no Hospital Universitário Gaffrée-Guinle - Escola de Medicina e Cirurgia - Universidade Federal do Estado do Rio de Janeiro (UNIRIO) 
laparotomia dada a impossibilidade de dissecção segura decorrente do intenso processo inflamatório da VB, aderida ao cólon transverso, ao duodeno e ao omento maior (Figura 1C); a colangiografia per-operatória: normal. Anátomo-patológico: VB medindo 13,0 x $6,0 \mathrm{~cm}$, com parede de $8,0 \mathrm{~mm}$ de espessura, apresentando laceração com $4,0 \mathrm{~cm}$ de extensão comprometendo parcialmente a parede sem alcançar a serosa. Havia coágulo antigo na luz do órgão (Figura 1D). Diagnóstico histopatológico: colecistite aguda. A alta ocorreu 48 horas após a operação.

\section{DISCUSSÃO}

A lesão da árvore biliar extra-hepática conseqüente ao trauma fechado do abdome é rara ${ }^{2-5}$. Há $0,63 \%$ de comprometimento da VB no trauma abdominal, sendo $0,86 \%$ em pacientes com ferida penetrante e $0,37 \%$ nas vítimas de trauma fechado ${ }^{1}$. Nos diferentes tipos de traumatismo abdominal o envolvimento da VB está associado a uma ou mais lesões intra-abdominais. Nesta circunstância, o órgão mais acometido é o fígado ${ }^{1,4}$. Há relatos citando danos isolados da VB no trauma fechado do abdome como no caso ora descrito ${ }^{2,3,5}$.

Dentre as lesões traumáticas da VB a laceração é a forma mais freqüente, já a colecistite traumática é bem mais rara, representando cerca de $3 \%$ dos $\operatorname{casos}^{4}$. A colecistite aguda traumática (CAT) resulta da presença de sangue intraluminal na VB causada por lesão da sua parede ou por ferida hepática seguida de sangramento para o interior da VB, formação de coágulo e obstrução do cístico ${ }^{2,4}$, como o observado no presente caso.

O diagnóstico do comprometimento da VB resultante do trauma fechado do abdome geralmente é firmado durante a laparotomia exploradora ${ }^{4,5}$. Deve-se isto a existência freqüente de outras lesões viscerais mais graves que se sobrepõem àquela da VB. Quando a laparotomia não é realizada pode ocorrer um intervalo de uma a seis semanas para que seja estabelecido o diagnóstico da lesão traumática da VB, como foi por nós observado. Na CAT pode ocorrer icterícia, hematemese e melena ${ }^{2,4}$. No presente caso houve dois episódios de melena atribuídos a hemobilia originada na laceração da parede da VB. Os exames de imagem são capazes de identificar pequenas coleções líquidas no espaço peri-colecístico, espessamento parietal e material de alta densidade (TC), hipoecóico (US) ou sinal de intensidade mista (RNM) no interior da VB, estes compatíveis com coágulos sanguíneos em vários estágios de degradação $0^{2,5}$.

O tratamento varia da simples observação, em casos selecionados, à colecistectomia, dependendo da gravidade do trauma da VB e da condição clínica do paciente ${ }^{2,4}$. A conduta expectante é adotada no trauma isolado da VB sem perfuração da mesma, desde que o diagnóstico possa ser feito por exame de imagem. Durante a laparotomia é possível conservar a VB na contusão moderada e na avulsão parcial desde que ela esteja intacta. A colecistectomia está indicada na avulsão completa, na lesão grave da $\mathrm{VB}$, na ruptura da artéria cística, na presença de doença prévia da VB, na CAT traumática e também quando a anatomia do pedículo hepático for obscura ou em pacientes extremamente graves que necessitem drenar bile e/ou sangue ${ }^{4}$. Neste paciente optou-se pelo acesso vídeolaparoscópico, entretanto, devido ao grau de dificuldade encontrado decidiu-se pela conversão do procedimento, como o relatado por outros autores ${ }^{3}$. A via vídeolaparoscópica alcança êxito quando a operação é executada precocemente, pois não há aderências fortes entre VB e as estruturas adjacentes ${ }^{2}$.

Geralmente, o prognóstico dos pacientes vítimas de trauma fechado da VB é favorável, especialmente se a partir da suspeita clínica a investigação complementar detectar de pronto o problema, se não houver comprometimento visceral grave associado e se o tratamento adequado for instituído precocemente.

\begin{abstract}
Isolated gallbladder injury following abdominal blunt trauma is rare and early diagnosis is difficult to make, particularly when no other organ is injured. However, ultrasonography is valuable for investigating gallbladder injuries. We report a case of isolated gallbladder blunt trauma presented as acute cholecystitis with hemobilia. In isolated blunt traumatic injury to the gallbladder, treatment options vary depending on the specific injury. The characteristics of blunt trauma injuries to the gallbladder and their appropriate management are discussed (Rev. Col. Bras. Cir. 2008; 35(5): 346-348).
\end{abstract}

Key words: Acute cholecystitis; Blunt abdominal trauma; Hemobilia; Intra-gallblader hemorrhage.

\section{REFERÊNCIAS}

1. Zantut LFC, Machado MAC, Volpe P, Poggetti RS, Birolini D. Lesão de vesícula biliar em trauma abdominal: análise de 32 casos. Rev Hosp Clin Fac Med Univ São Paulo. 1993; 48(6):2838 .

2. Kirshtein B, Lantsberg L, Duchno L, Roy-Shapira A, Barky I. Posttraumatic acute cholecystitis caused by intra-gallbladder hemorrhage in a patient with anticoagulant therapy. Eur J Trauma. $2002 ; 28(4): 263-5$
3. Nishiwaki M, Ashida H, Nishimura T, Kimura M, Yagyu R, Nishioka A, Utsunomiya J, Yamamura T. Posttraumatic intragallbladder hemorrhage in a patient with liver cirrhosis. J Gastroenterol. 1999; 34(2):282-5.

4. Sharma O. Blunt gallbladder injuries: Presentation of twentytwo cases with review of the literature. J Trauma. 1995; 39(3):576-80.

5. Carrillo EH, Lottemberg L, Saridakis A. Blunt Traumatic Injury of the Gallbladder. J Trauma. 2004; 57(8):408-9. 
Como citar este artigo:

Salomão RM, Magalhães NC, Silva FV, Iglesias AC. Colecistite aguda decorrente de hemorragia intraluminar da vesícula biliar após trauma abdominal fechado. Rev Col Bras Cir. [periódico na Internet] 2008; 35(5). Disponível em URL: http://www.scielo.br/rcbc
Endereço para correspondência:

Antonio Carlos Iglesias

Rua Jorge Rudge 120, Bloco 2, Apto. 1007

20550-220 - Rio de Janeiro - RJ

E-mail: iglesias@momentus.com.br 